\title{
Mutual relationships of suspended sediment, turbidity and visual clarity in New Zealand rivers
}

\author{
DEBORAH J. BALLANTINE ${ }^{1}$, ANDREW O. HUGHES ${ }^{2} \&$ \\ ROBERT J. DAVIES-COLLEY ${ }^{2}$ \\ 1 Department of Environmental Science, Xi'an Jiaotong-Liverpool University, 111 Ren'ai Road, Dushu Lake Higher \\ Education Town, Suzhou Industrial Park, Suzhou 215123, China \\ deborah.ballantine@,xjtlu.edu.cn \\ 2 Aquatic Pollution, National Institute for Water and Atmospheric Research (NIWA), Hamilton, New Zealand
}

\begin{abstract}
Many river water quality monitoring programmes do not measure suspended particulate matter (SPM) mass concentrations despite significant interest in its multiple effects on aquatic ecosystems. Regular monthly sampling usually intercepts rivers in baseflow when suspended sediment mass concentrations and fluxes are relatively low and not of particular interest. New Zealand's National Rivers Water Quality Network (NRWQN) is probably typical in not measuring SPM mass, although visual clarity and nephelometric turbidity are routinely measured. In order to better characterize SPM in NZ rivers, total suspended sediment (TSS) was temporarily added to the NRWQN. Turbidity, visual clarity and TSS are mutually inter-related over all 77 sites, although with considerable data scatter. However, within individual rivers turbidity and visual clarity are typically fairly closely related to TSS and provide fair to excellent surrogates. Therefore, TSS need not be measured routinely because it can be estimated with sufficient precision for many purposes from visibility or turbidity.
\end{abstract}

Key words total suspended sediment; visual clarity; turbidity; river monitoring

\section{INTRODUCTION}

Suspended sediment has long been recognised as a major cause of impairment in fluvial and downstream ecosystems. While fine sediment is part of a natural river system (Ryan 1991), when present in excessive amounts, it is both a pollutant in its own right and a vector for other pollutants. Instances of human-induced soil erosion and related transport in rural and urban systems are well documented (e.g. Rodriguez-Blanco et al. 2013, Franz et al. 2014). High concentrations of fine suspended sediment within rivers and streams can lead to mortality of fish during the embryonic life stage and can considerably extend the larval phase (Greig et al. 2005, Wenger et al. 2014). Reduced visual clarity owing to fine sediment constrains behaviour of fish and birds and degrades recreational amenity (Davies-Colley and Smith 2001). Fine sediment also reduces light penetration into waters and constrains primary productivity (Kumar et al. 2010, Perez et al. 2013). Fine sediment accumulation on the bed of rivers changes macroinvertebrate community composition, by favouring some macroinvertebrates at the expense of others (Wood and Armitage 1997). As a vector for pollutants, sediment has a key role in transporting and storing phosphorus, metals, contaminant microbes, and organic and inorganic pollutants (Shi et al. 2005, Ballantine et al. 2008, 2009, Droppo et al. 2009, Tao et al. 2014).

Given its potential to degrade freshwater systems, it is important to improve our understanding of fine sediment behaviour in rivers. However, long-term monitoring of suspended sediment concentrations as a component of state-of-environment (SoE) freshwater monitoring programmes seems unusual, probably because of the comparative expense of the TSS assay and the fact that routine monitoring usually intercepts rivers in baseflow when TSS is low and of minor interest. Instead, there is much greater interest in monitoring sediment loads, which requires sediment measurements targeted to stormflows. Another issue is the TSS analysis cost which is comparatively high (Davies-Colley et al. 2014).

We would argue, however, that there is value in meshing suspended sediment monitoring with that of other water quality variables (at least in brief campaigns), so as to increase our understanding of suspended particulate matter (SPM) composition and relationships to particulate aspects of water quality. 
Optical variables are appealing as surrogates for suspended sediment, being cheap and amenable to continuous monitoring (Davies-Colley et al. 2014). Nephelometric turbidity, an index of the scattering of light by suspended materials, has frequently been used as a surrogate for suspended sediment in a range of environmental settings. For example, Line et al. (2013) estimated suspended solids from turbidity in Robeson Creek, North Carolina, USA, while Chanson et al. (2008) used turbidity and acoustic backscatter intensity as surrogate measures of suspended sediment in a small subtropical estuary in eastern Australia. Other authors have extended their studies to include not only suspended sediment predictions, but also to estimate concentrations of sediment-related variables; e.g. Rugner et al. (2013) and Stubblefield et al. (2007) used turbidity as a proxy for total suspended solids and particle-associated pollutant transport, in studies of small catchments in southwest Germany and the Lake Tahoe basin (USA), respectively. Turbidity is also often measured in routine water quality monitoring, probably as a surrogate for visual clarity although this is quite capable of direct measurement.

Visual clarity is much less often measured in routine water quality work than turbidity, but Davies-Colley and Smith (2001) have shown that visual clarity, measured by the black disc technique, relates far more 'intuitively' to human users of water than turbidity. Furthermore, visual clarity for humans is numerically almost identical to that for birds and fish, such that visual clarity is a valuable indicator of the 'reactive distance' of these animals (e.g. Newcombe 2003). Visual clarity is arguably preferable to turbidity in the sense that the former is a 'proper' scientific quantity (measured in SI units - metres - and related robustly to inherent optical properties, e.g. Zaneveld and Pegau (2003), while turbidity is merely an arbitrary index of light scattering. Arguably, visual clarity is a more appropriate variable than turbidity for enumeration of environmental limits (Davies-Colley and Smith 2001, Davies-Colley et al. 2014). A novel aspect of this paper is our presentation of relationships between TSS and visual clarity as well as TSS and turbidity.

Sediment mass concentration has not been measured routinely in the NRWQN since its inception in 1989, mainly for reasons of cost, and because surrogates (visual clarity and turbidity) were available (Davies-Colley et al. 2011). However, TSS measurements were added temporarily in 2011 so as to provide a dataset for relating 'particulate' water quality to mass of particulates (Davies-Colley et al. 2014). Davies-Colley et al. (2014) have reported mutual relationships of TSS, turbidity and visual clarity across multiple sites in the NRWQN. In this contribution we emphasise these relationships within individual NRWQN rivers, and draw conclusions about the value of pairing sediment assays with water quality monitoring and the routine use of optical variables in SoE monitoring.

\section{MATERIALS AND METHODS}

The NRWQN is a valuable test bed for studying relationships between water quality variables (Davies-Colley et al. 2011). This network was established in 1989 and consists of 77 sites on 35 comparatively large river systems distributed through the North and South Islands of New Zealand. Locations of the 77 NRWQN sites are shown in figures given by Davies-Colley et al. (2011) and Ballantine and Davies-Colley (2014). The aggregate catchments of the NRWQN cover half of New Zealand's land area, and catchments vary widely in geology, climate, soils and land cover, and provide a good representation of the variability found across the country. Monthly measurements in the NRWQN are taken of 14 basic water quality variables, including the optical variables: visual clarity, nephelometric turbidity and coloured dissolved organic matter (For further detail see Davies-Colley et al. 2011).

Visual clarity is measured during routine NRWQN sampling visits by the in situ black disc method (Davies-Colley 1988). Briefly, the observer wades into the river and records the extinction distance of a black disc viewed horizontally under the water surface using a simple periscope fitted with a $45^{\circ}$ mirror (Davies-Colley 1988, Davies-Colley et al. 2003). Zaneveld and Pegau (2003) have shown that visual clarity measurement by the black disc method is a 'robust' visibility parameter in the sense that it relates accurately to the fundamental optical properties of water. 
Water samples (including a special sample for particulate measurements) were collected within a few minutes of the visual clarity measurements, and sent by overnight courier to the NIWA laboratory in Hamilton for measurement (usually within 24 hours) of TSS and other assays of SPM as well as the routine water quality and optical variables. Nephelometric turbidity was measured on a Hach 2100AN nephelometer as part of routine NRWQN analysis.

TSS was determined by a standard gravimetric method (APHA 1985; Method 2540D). Analysis involved filtering a well-shaken subsample of the sediment water sample through a glass fibre filter. To cope with the low TSS concentration in clear rivers at baseflow, 'oceanographic' modifications were adopted, including the use of fairly large volume samples (up to $5 \mathrm{~L}$ ) to obtain sufficient residue on $25 \mathrm{~mm}$ GF/F 3 filters (Davies-Colley et al. 2014). The filter and residue were dried at $103-105^{\circ} \mathrm{C}$, and then weighed on an analytical balance.

\section{Statistical analysis}

Data for TSS, visual clarity and turbidity were analysed for correlations (Spearman's) between variables for the entire dataset and at individual sites using IBM SPSS version 21. Regression was also carried out on log-transformed (log base 10) data to evaluate how effectively TSS concentrations could be predicted using either visual clarity on its own, or combined with turbidity, at individual sites.

\section{RESULTS}

\section{Sediment and related optical variables}

Results already presented elsewhere (Davies-Colley et al. 2014) showed that there were significant correlations between visual clarity, TSS, turbidity and VSS data for 2011 (Table 1). There were highly significant inverse relationships between clarity, turbidity and TSS. Clarity and turbidity were strongly (negatively) inter-related, though TSS is slightly less strongly related to both clarity and turbidity. Davies-Colley et al. (2014) have presented mutual scatterplots for each combination of TSS, turbidity and visual clarity across all sites; a scatterplot of TSS and visual clarity shows that, while the correlation is strong, there is still appreciable data scatter (Fig. 1).

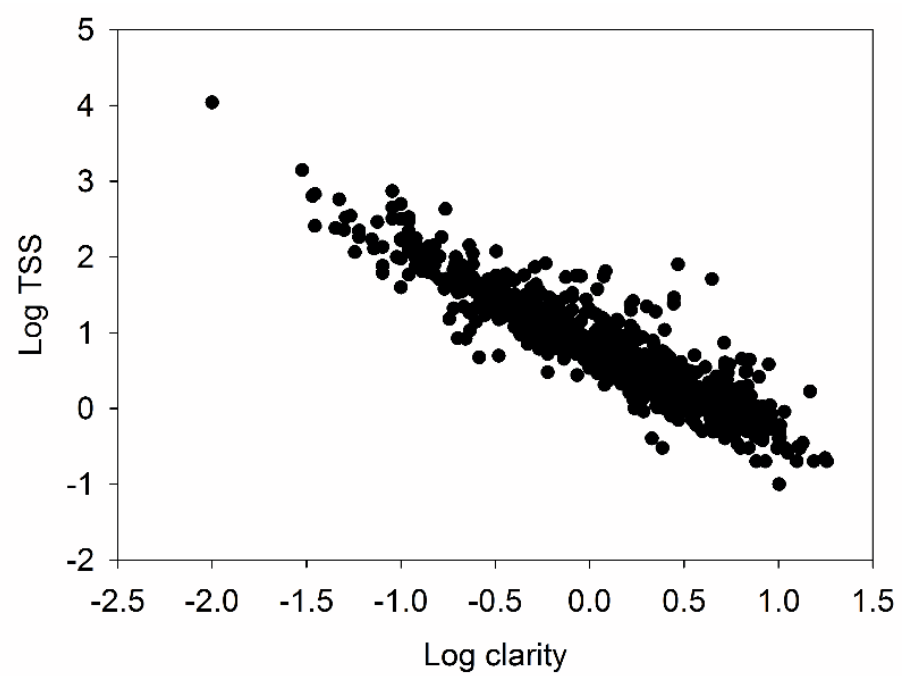

Fig. 1 Scatterplot of TSS $v s$ visibility for data for 12 months across all 77 sites.

Table 1 Correlations between optical variables; ** indicates a significant correlation at the 99\% level.

\begin{tabular}{llcr}
\hline & Visual clarity & Turbidity & TSS \\
\hline Visual clarity & & $-0.948^{* *}$ & $-0.920^{* *}$ \\
Turbidity & $-0.948^{* *}$ & & $0.871^{* *}$ \\
TSS & $-0.920^{* *}$ & $0.871^{* *}$ & \\
\hline
\end{tabular}


Regression analysis of log-transformed variables showed that visual clarity was a good predictor of TSS and turbidity, and that turbidity was also a good predictor of TSS, with high $R^{2}$ values, but error values indicate a high error in estimations of TSS from visibility and turbidity overall (Table 2). To emphasise the amount of variability between individual sites, scatterplots of TSS vs visibility for two contrasting sites, are shown in Fig. 2. At site NN4, there is a very close relationship between visibility and turbidity, while at site WH1, there is a very weak relationship.
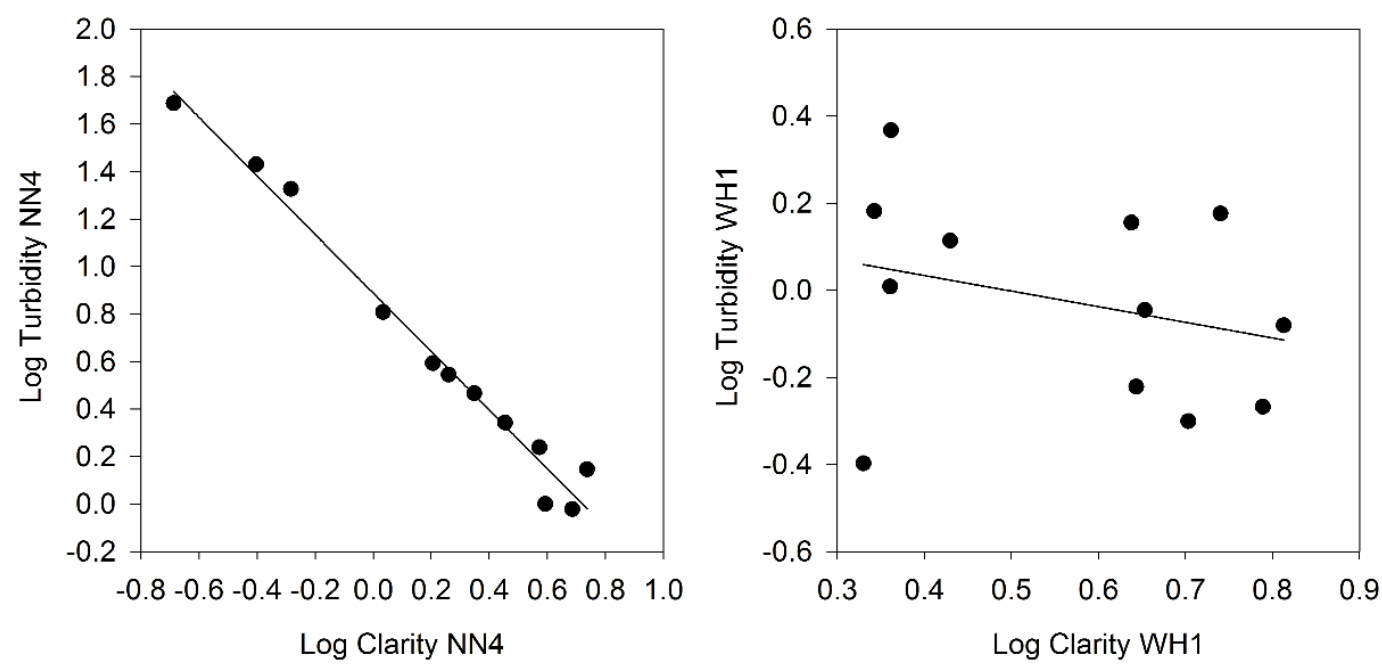

Fig. 2 Example scatterplots of TSS vs visibility for two contrasting sites, one with a close relationship and one with a weak relationship. (Linear regression lines are shown.)

Table 2 SE values from regression analysis of log-transformed optical variables.

\begin{tabular}{lll}
\hline & Log turbidity & Log TSS \\
\hline Log visual clarity & 0.193 & 0.266 \\
Log turbidity & & 0.313 \\
\hline
\end{tabular}

Despite the close correlation over three orders of magnitude, TSS predictions from optical variables (or vice versa) are imprecise. However, the question arises as to whether such relationships are more predictive in individual rivers in which SPM optics might be expected to be less variable and trend systematically with state-of-flow (Davies-Colley et al. 2014).

On a site-by-site basis, clarity was significantly and inversely correlated with turbidity at 71 of the 77 river sites; sites at which there was no significant relationship included four lake-fed sites. On a site-to-site basis, clarity was able to predict turbidity effectively at most sites. The median $R$ value for the 77 sites was 0.95 , the median $R^{2}$ value was 0.9 , and the median SE was $0.147 \log$ NTU (range 0.058-0.7771). The distribution of the $R$ and SE values from regression of visual clarity and turbidity is shown in Fig. 3.

There were also significant inverse correlations between visual clarity and TSS at 67 of the 77 river sites; the sites at which there was no significant relationship included four lake-fed sites. On a site-to-site basis, clarity remained a good predictor of TSS, with a median R value of 0.94 , a median $R^{2}$ value of 0.875 , and a median RMSE of $0.168 \mathrm{~g} / \mathrm{m}^{3}$ (range $0.045-0.573$ ).

At three lake-fed sites, there were no significant relationships between either visual clarity and TSS, or visual clarity and turbidity.

Overall, there was less error associated with predicting TSS and turbidity from visual clarity on a site-by-site basis than for the entire data set. On a site-by-site basis, the median $R$ value was 0.911 , the median $R^{2}$ value was 0.830 , and the median SE was 0.182 (range 0.087-0.577). The distribution of $R$ and SE values for all sites is shown in Fig. 3. The plots indicate that $R$ values tend to be close to 1 , and SE values tend to be low, both of which support the conclusion that all three variables are closely related in individual rivers. 

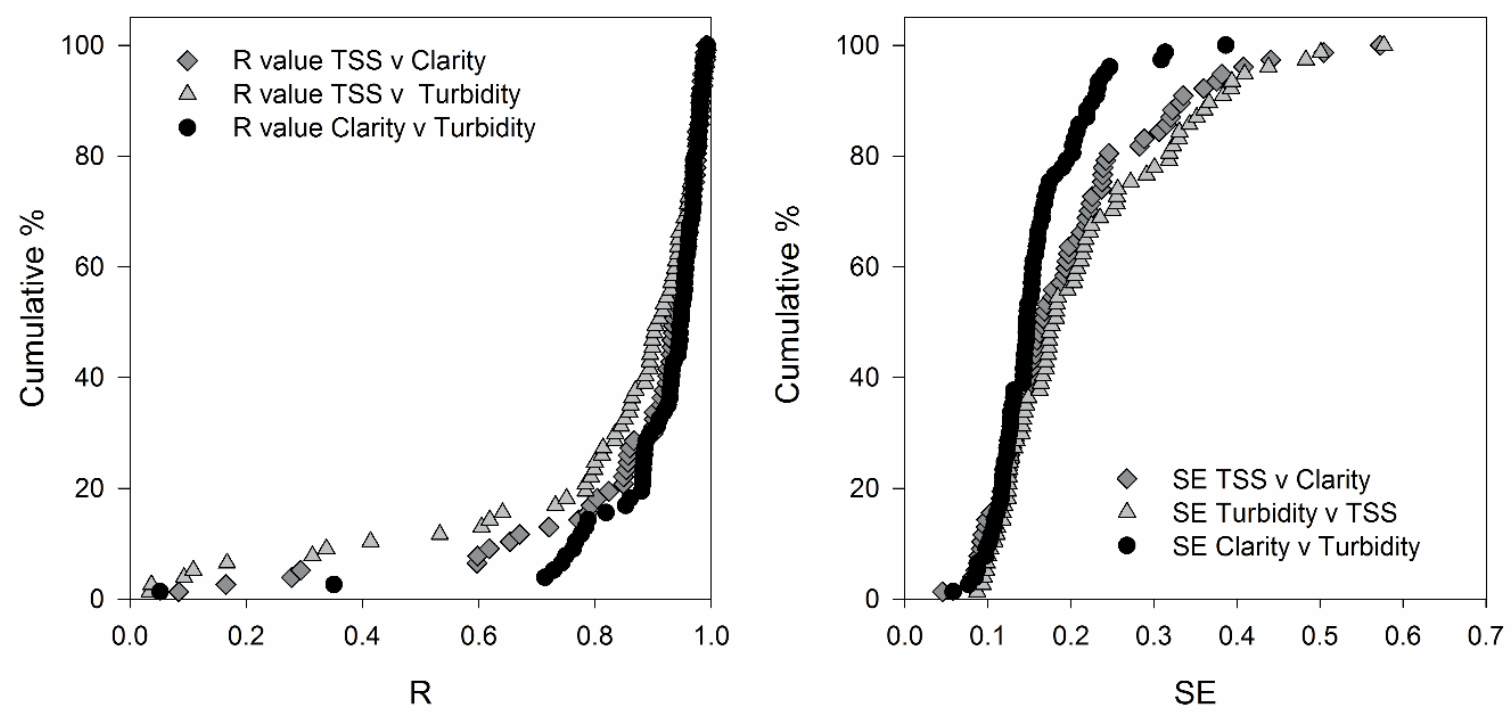

Fig. 3 Distribution plots of the Pearson's correlation coefficient, $R$, and standard error (SE) of the regressions for TSS $v s$ visibility, TSS $v s$ turbidity and visibility $v s$ turbidity.

\section{DISCUSSION}

TSS is strongly related (non-linearly) to the optical variables within particular rivers, so, TSS can be estimated with sufficient accuracy for many purposes, if needed, from visual clarity or turbidity at particular river sites. Our analysis suggests that there is no need to monitor TSS routinely and indefinitely in river SoE monitoring.

Statistical exploration of paired data for optical variables and TSS suggests that there are strong inter-relationships. Relationships of turbidity and TSS are well known, of course, and often used (on a site-by-site basis) for estimating TSS from turbidity that is sometimes continuously monitored. Relationships of TSS and visual clarity are more novel, and are of considerable interest in that it is possible to estimate the light attenuation cross-section $\left(\mathrm{C}, \mathrm{m}^{2} / \mathrm{g}\right)$ from the beam attenuation coefficient $\left(\mathrm{m}^{-1}\right)$ estimated from visual clarity divided by TSS concentration $\left(\mathrm{g} / \mathrm{m}^{3}\right)$ (Davies-Colley et al. 2014).

Across all sites, visual clarity is strongly correlated with TSS and turbidity as has been reported by Davies-Colley et al. (2014). However, while the $R^{2}$ values are relatively high, SE values are also high, suggesting that the relationships are not very precisely predictive. SE values from regression analysis used to predict TSS and turbidity from visual clarity at individual sites are usually appreciably lower, however, suggesting that visual clarity or turbidity could be used as a surrogate for TSS once site-specific regression relationships are developed.

The relationships of TSS, turbidity and visibility tend to be comparatively weak for lake-fed sites in which SPM and other light-attenuating constituents vary less markedly than in more normal rivers.

Data for this study was mainly collected in normal flow conditions; to make the relationships more robust, it would be useful to add more measurements taken from high flows. A campaign is currently underway to deliberately sample NRWQN sites in elevated flow so as to extend the mutual relationships between TSS and its optical surrogates.

The most useful indicators in large scale SoE monitoring programmes should be: (1) quantifiable over time, (2) sensitive to potential impacts, (3) cost effective, (4) easily measured and interpreted, (5) linked to assessment endpoints, and (6) benchmarked against reference values (Intergovernmental Task Force on Monitoring Water Quality 1995). While visual clarity is included in most regional water quality monitoring in New Zealand, it is rarely included in routine river water quality monitoring programmes elsewhere. As a water quality variable, it has many 
benefits: it meets the requirements outlined above for a useful indicator in a monitoring programme, and this study has shown that it is strongly related to a number of other variables for which laboratory analysis is traditionally required. For example, we have demonstrated that visual clarity is strongly related to TSS measurements, a variable which is expensive, labour intensive and time-consuming to include in ongoing monitoring programmes (Pavanelli and Bigi 2005). TSS need not be measured routinely or indefinitely, since it is relatively expensive (about fourfold higher than visibility or turbidity measurement (Davies-Colley and Smith 2001)) and largely redundant in SoE monitoring, given that rivers are usually intercepted at baseflow when TSS is low. Based on the strong relationships shown in this study, we conclude that initiatives, such as the temporary addition of TSS to the entire network, are useful to collect information of this nature. This unique dataset may provide new insights into the effects of sediment in freshwater systems.

This study shows that there are benefits in meshing sediment measurements with routine water quality monitoring, at least in brief campaigns. For example, Hughes et al. (2014) conducted visual clarity measurements on (diluted) auto-samples over stormflow events, to extend the application of sediment load measurements and permit analysis of optical impacts on downstream receiving waters. Further, visibility is a valuable variable that is of great interest in its own right, and is better than turbidity (or TSS) for enumerating environmental limits (Davies-Colley and Smith 2001). As such, it deserves to be more routinely measured as part of general water quality surveys.

\section{CONCLUSION}

Pairing of TSS measurements with (routinely measured) visual clarity and turbidity has revealed strong interrelationships both across and within sites. At individual sites the relationships are sufficiently precise to be predictive suggesting that (relatively expensive) TSS need not be measured routinely but can be estimated from (cheap) optical measures (turbidity or visibility) if required. Visibility is not yet routinely measured as part of water quality in most countries, but its inclusion in NZ's NRWQN for more than 25 years demonstrates its value. Inclusion of visibility in routine water quality both obviates the need to measure TSS and consigns turbidity to a mere supporting variable role.

Acknowledgements We thank the NIWA field teams for special collection of samples for analysis of TSS and other SPM variables as an add-on to routine NRWQN operations. Mike Crump, Graham Bryers and staff of the NIWA water quality laboratory at Hamilton are thanked for many SPM analyses.

\section{REFERENCES}

APHA (1985) Standard Methods for the Examination of Water and Wastewater. American Public Health Association, American Water Works Association Water Pollution Control Federation, Washington, D.C.

Ballantine, D.J. and Davies-Colley, R.J. (2014) Water quality trends in New Zealand rivers: 1989-2009. Environ. Monit. Assess. 186, 1939-1950.

Ballantine, D.J., et al. 2008) The phosphorus content of fluvial suspended sediment in three lowland groundwater-dominated catchments. Journal of Hydrology 357, 140-151.

Ballantine, D.J., et al. (2009) The content and storage of phosphorus in fine-grained channel bed sediment in contrasting lowland agricultural catchments in the UK. Geoderma 151, 141-149.

Chanson, H., Takeuchi, M., and Trevethan, M. (2008) Using turbidity and acoustic backscatter intensity as surrogate measures of suspended sediment concentration in a small subtropical estuary. Journal of Environmental Management 88, 14061416.

Davies-Colley, R.J. (1988) Measuring water clarity with a black disc. Limnology and Oceanography 33, 616-623.

Davies-Colley, R.J., et al. (2014) Light attenuation - a more effective basis for the management of fine suspended sediment than mass concentration? Water Science and Technology Available online 24 February 2014.

Davies-Colley, R.J. and Smith, D.G. (2001) Turbidity, suspended sediment and water clarity: a review. Journal of the American Water Resources Association 37, 1085-1101.

Davies-Colley, R.J., et al. (2011) Twenty years of New Zealand's National Rivers Water Quality Network: Benefits of careful design and consistent operation. Journal of the American Water Resources Association 47, 750-771.

Davies-Colley, R.J., Vant, W.N.,and Smith, D.G. (2003) Colour and Clarity of Natural Waters. Science and Management of Optical Water Quality. Blackburn Press, Caldwell, New Jersey, USA. 
Droppo, I.G., et al. (2009) Dynamic existence of waterborne pathogens within river sediment compartments. Implications for water quality regulatory affairs. Environmental Science \& Technology 43, 1737-1743.

Franz, C., et al. (2014) Sediments in urban river basins: Identification of sediment sources within the Lago Paranoa catchment, Brasilia DF, Brazil - using the fingerprint approach. Science of the Total Environment 466, 513-523.

Greig, S.M., Sear, D.A., and Carling, P.A. (2005) The impact of fine sediment accumulation on the survival of incubating salmon progeny: Implications for sediment management. Science of The Total Environment 344, $241-258$.

Hughes, A.O., Davies-Colley, R.J., and Elliott, A.H. (2014) Measurement of light attenuation extends application of suspended sediment concentrations and loads for rivers. Sediment Dynamics from the Summit to the Sea (Proceedings of a symposium held in New Orleans, Louisiana, USA, 11-14 December 2014) IAHS Publ. 367. This volume.

Intergovernmental Task Force on Monitoring Water Quality (1995) The Nationwide Strategy for Improving Water Quality Monitoring in the United States. Final Report of the Intergovernmental Task Force on Monitoring Water Quality Technical Appendix E. Department of Interior, U.S. Geological Survey Reston, Virginia., pp. 95-742.

Kumar, S.P., et al. (2010) Is the biological productivity in the Bay of Bengal light limited? Current Science 98, $1331-1339$.

Line, D.E., Hall, K.R. and Blackwell, J.D. (2013) Estimating suspended solids from turbidity in the Robeson Creek, NC Watershed. Journal of the American Water Resources Association 49, 1412-1420.

Pavanelli, D. and Bigi, A. (2005) Indirect methods to estimate suspended sediment concentration: reliability and relationship of turbidity and settleable solids. Biosystems Engineering 90, 75-83.

Perez, G.L., Lagomarsino, L., and Zagarese, H.E. (2013) Optical properties of highly turbid shallow lakes with contrasting turbidity origins: The ecological and water management implications. Journal of Environmental Management 130, 207220.

Rodriguez-Blanco, M.L., Taboada-Castro, M.M., and Taboada-Castro, M.T. (2013) Linking the field to the stream: Soil erosion and sediment yield in a rural catchment, NW Spain. Catena 102, 74-81.

Rugner, H., et al. (2013) Turbidity as a proxy for total suspended solids (TSS) and particle facilitated pollutant transport in catchments. Environmental Earth Sciences 69, 373-380.

Ryan, P.A. (1991)Environmental effects of sediment on New Zealand streams: a review. New Zealand Journal of Marine and Freshwater Research 25, 207-221.

Shi, Z., et al. (2005) Contamination of rivers in Tianjin, China by polycyclic aromatic hydrocarbons. Environmental Pollution $134,97-111$.

Stubblefield, A.P., et al. (2007) Use of turbidometry to characterize suspended sediment and phosphorus fluxes in the Lake Tahoe basin, California, USA. Hydrological Processes 21, 281-291.

Tao, Y.Q., et al. (2014) Deposition and regional distribution of HCHs and p,p '-DDX in the western and southern Tibetan Plateau: records from a lake sediment core and the surface soils. Environmental Science and Pollution Research 21, $1875-$ 1883.

Wenger, A.S., et al. (2014) Suspended sediment prolongs larval development in a coral reef fish. The Journal of Experimental Biology 217.

Wood, P.J. and Armitage, P.D. (1997) Biological effects of fine sediment in the lotic environment. Environmental Management 21, 203-217.

Zaneveld, J.R. and Pegau, W. (2003) Robust underwater visibility parameter. Optical Express 11, 2997-3009. 